\title{
Study on the Conservation Planning of Vernacular Landscape in Village Planning in the Context of Multi-regulation Integration- The Case of Changlong Village in Pinggui District, Hezhou City
}

\author{
Shuaiqi Yang ${ }^{1, *}$, Jinye Wang ${ }^{2}$ \\ ${ }^{1}$ College of Tourism and Landscape Architecture, Guilin University of Technology, Guilin, Guangxi, China \\ ${ }^{2}$ College of Tourism and Landscape Architecture, Guilin University of Technology, Guilin, Guangxi, China
}

\begin{abstract}
As one of the important concentrated manifestations of Chinese rural culture, vernacular landscape is related to the success or failure of new rural construction and village planning. How to protect the existing vernacular landscape in the practical village planning advocated by "multi-planning" and how to play the role of vernacular landscape in supporting development and protecting cultural heritage is one of the important tasks of village planning. This paper takes Changlong Village in Pinggui District, Hezhou City, Guangxi Province, as an example to explore and study the issue of planning the native landscape of Changlong Village in the multi-planning village planning, so as to provide technical support for the scientific protection and reasonable development and utilization of the native landscape for rural revitalization, and to provide reference and reference for the native landscape planning in the village planning of similar areas in China.
\end{abstract}

\section{Introduction}

Since the report of the 19th National Congress put forward the strategy of "rural revitalization", the vernacular landscape of rural areas has received more and more attention, and on May 23, 2019, the Central Committee of the Communist Party of China and the State Council officially announced the Opinions on Establishing a Territorial Spatial Planning System and Supervising its Implementation, and the status of village planning has been elevated. As early as the 1940s, the study of vernacular landscape began in Western countries, and Jackson divided cultural landscape into political landscape and vernacular landscape, and vernacular landscape with folklore ${ }^{[1]}$. European scholars tend to the cultural connotation of vernacular landscapes and the interaction between people and landscapes through various mean ${ }^{[2]}$. The Netherlands carries out large scale "intervention landscapes"[3]. China started to study vernacular landscape from the 1980s, and Yu Kongjian expounded the meaning of vernacular landscape, and Liu Xinyan studied the expression of vernacular landscape elements. Hou Xiaolei and Guo Wei decomposed vernacular landscape into multi-layered composite systems from the perspective of landscape gardening ${ }^{[4]}$. This provides a theoretical basis for the deep excavation and landscape conservation of vernacular landscapes nowadays. However, the previous research is more of a theoretical means. This paper combines vernacular landscape conservation with village planning to explore the methods of vernacular landscape conservation under the guidance of village regulations, and provides reference for other villages in the context of rural revitalization.

\section{2 "Multi-regulation" and village planning development}

In June 2019, the Ministry of Natural Resources of the People's Republic of China issued the Circular on Strengthening Village Planning for Rural Revitalization (hereinafter referred to as the Circular), which clarifies the general requirements and task objectives of village planning and emphasizes the "integration of multiple regulations". The Circular on Strengthening Village Planning for Rural Revitalization (hereinafter referred to as "the Circular") was issued to clarify the general requirements and task objectives of village planning, emphasizing the "integration of multiple regulations". The Circular proposes that village planning, as the detailed planning of rural areas in the spatial planning of the land, should be based on the requirements of "integration of multiple regulations", from the aspects of settlement construction, industrial layout, environmental improvement, ecological protection, historical and cultural inheritance, land use, etc., and integrate the village land use planning, village construction planning and industrial development planning, etc., as well as combine with the rural planning of each village. Organic integration, and combined with the regional characteristics of each village, according to local conditions for planning. The main tasks of village planning include ecological restoration and protection, basic farmland protection, industrial layout development, recent construction projects and other eight categories. The Notice puts

\footnotetext{
* Corresponding author: y18939586273@163.com
} 
forward new requirements for the preparation of the plan: first, it emphasizes the dominant position of villagers, village party organizations and village committees; second, it emphasizes openness and wide participation, mobilizing the enthusiasm of universities and colleges, planning and design institutions, sages and celebrities, etc., to participate in the preparation of village planning; third, it takes into account local conditions, combining the actual situation of each village with flexibility and adaptability, and looking for planning ideas suitable for the local area; fourth, the planning results are expressed concisely, so that "one map, one table, one rule", to ensure that everyone can read, understand, implement and supervise.

\section{Vernacular landscape conservation planning in multi-regulation village planning}

\subsection{Analysis of the relationship between vernacular landscape planning and village planning}

"Vernacular landscape refers to the way people in different regions carry out activities for natural processes, land, and land space patterns in order to adapt to their respective lifestyles, and is a composite system that contains local nature and culture as a display of people's lifestyles in their respective regions on the earth." ${ }^{[5]}$ Vernacular landscape conservation planning generally refers to rural landscape planning, which is mostly integrated in village planning, and rarely has a separate vernacular landscape planning or vernacular landscape conservation planning. Research on rural landscape planning can be traced back to the 1980s, mainly from three major aspects of geography, landscape ecology, and land planning practice. As an important productive resource, rural landscape resources have three levels of functions, such as satisfying agricultural production, maintaining ecological balance, and providing tourism resources ${ }^{[6]}$. Vernacular landscape planning is the rational arrangement of the geographical space of rural landscape resources through planning and design to establish a composite sustainable rural landscape system with health, recreation, education, leisure and safety functions for rural residents.

Village planning can be essentially divided into three levels of planning: ecological, production and living. Native landscape resources are closely related to ecological protection, production development and living environment creation in village planning, and native landscape protection planning occupies an important position in village planning. In terms of production, it should give play to the productive role of native landscape resources, strengthen the integrated development of agriculture, forestry, animal husbandry and fishery in rural areas, and optimize sightseeing agricultural parks and picking parks, etc. In terms of ecology, it should strengthen the protection of good natural ecological environment and the treatment of polluted environment, and build In the ecological aspect, we should strengthen the protection of good natural ecological environment and the treatment of polluted environment, build a natural ecological system with perfect functions and richness, provide good development space and scientific research sites, etc.; in the living aspect, we should preserve the existing ancient buildings and traditional customs, etc. to preserve their historical atmosphere.

\subsection{Exploring the concept of vernacular landscape conservation planning}

Generally speaking, vernacular landscape planning is to establish a sustainable rural landscape protection system to meet people's diverse material and spiritual needs. Specifically, it includes agricultural-oriented productive landscape planning, rural architecture-centered settlement landscape planning and nature-based ecological landscape planning, which is based on the concept of "Symbiosis between people and landscape", with the production field ensuring agricultural production, the living field ensuring rural settlement, and the ecological field ensuring ecological balance to achieve triadic interaction, harmony and unity. The conservation of rural landscape requires the integration of multidisciplinary fields, sufficient understanding and grasp of landscape elements, as well as crossing two dimensions of time and space, and planning and design in the order of landscape survey, landscape ecological analysis, comprehensive evaluation, land use planning, and landscape planning and design, so as to realize the rationality of the content and structure of rural landscape conservation planning ${ }^{[7]}$.

\subsection{Selection of vernacular landscape conservation planning principles}

(1) Authenticity. Authenticity is to ensure that the local landscape remains "natural" potential, the local landscape is formed under the long-term historical process of human nature, must ensure its authenticity, present the original state of the landscape, a true reflection of the long-term history of the mutual relationship between man and nature. (2) Inheritance. Due to geographical differences and other factors, the local landscape is not the same everywhere, it must be protected and innovated, also on the basis of the original into the elements of the times, from different dimensions to deeply grasp the history and future fit. (3) Locality. In modern times, it is more common to see "a thousand villages", and it is a mistake to rigidly apply village planning to all places. Each rural area should combine local characteristics to create a colorful vernacular landscape, contributing to the "blossoming of a hundred flowers" pattern.(4) Sustainability. According to the meaning and concept of rural landscape conservation planning, sustainable rural landscape is "scenic village integration", "human landscape symbiosis", the various landscape elements in rural areas into a complete ecological cycle system. At the same time to grasp the planning of sustainable, that is, the relationship between the near-term planning and long-term planning, native landscape protection planning and other planning docking. (5) Economy. Compared with urban planning, village planning often receives less government financial support. 
Therefore, economic and technical indicators need to be considered in the planning process to ensure that it is within the operability range.

\subsection{Analysis of the content of vernacular landscape conservation planning}

As a systematic conservation planning, the vernacular landscape planning in the "multi-planning" village planning is divided into several aspects, such as site investigation, comprehensive analysis and evaluation, land use and site layout analysis, and landscape planning and design. (1) Site investigation and analysis. Adequate understanding of the planning area is the basis of planning, including the geographical location of the site, climatic factors, resource profile, historical context, human activities, etc. To make a reasonable planning, we must understand the interrelationship between human and nature, and realize the symbiosis of human and landscape. (2) Analysis and evaluation of landscape resources. Analysis is a step deeper than investigation, which requires not only grasping the basic design of the site, but also grasping various landscape elements in the site. In the planning process, to understand its cultural connotation and element symbols, while the understanding of the landscape elements for classification and evaluation of the summary. (3) Analysis of site structure layout. Combined with the national land survey data, to understand the proportion of each land type, especially the rural residential base, the basic farmland protection zone, ecological protection red line, urban development boundary, so as to provide land reasonableness analysis for landscape planning, the landscape planning of various types of elements integrated planning. (4) Landscape planning and design. Linking fragmented landscape elements with various natural ecological subsystems to form an orderly landscape sequence. In the planning and design process, public participation is implemented to reflect the villagers' wisdom and will in the planning content to truly grasp the actual situation.

\subsection{Exploration of vernacular landscape conservation planning methods}

Vernacular landscape planning mainly combines the "three living" spatial layout and optimization of village planning, classifying and grasping the three major spaces of production, ecology and life, and highlighting the individual development of rural areas. Production landscape planning is the rational use of sufficient productive vernacular landscape resources in rural areas; ecological landscape planning includes not only natural ecosystem planning, but also "ecological" planning, linking human and nature as a natural ecosystem; living landscape planning is to combine traditional customs, skills, traditional architecture, traditional life and other material and intangible vernacular landscape planning.
Traditional life and other material and immaterial native landscape resources are reasonably protected and developed, especially the cultural symbols of native landscape resources should be extracted and reproduced, so that villagers can see the mountains, see the water and remember their nostalgia. Vernacular landscape protection can also use compensatory means, alternative means, reproduction means to planning and design, for the destruction of the vernacular landscape for compensation and renewal, for some immaterial landscape elements to give material reproduction of its characteristics, the overall grasp of local conditions, realistic.

\section{Vernacular Landscape Conservation Planning in Changlong Village, Pinggui District, Hezhou City}

\subsection{Basic Overview}

Changlong Village is located in the north of Huangtian Town, west of Lining Village, east of Huangtianzhai Village, north of Xin Village, and south of Anshan Village. It is 3 kilometers from Huangtian Town Government, 7 kilometers from Pinggui District Government and 6 kilometers from the central city of Hezhou. About 500 meters to the west of the village committee is Hezhou Railway Station, and about 1 kilometer to the east is Gupo Mountain Avenue passing by. Changlong Village has abundant natural and human resources in its territory. The village has a subtropical monsoon climate with abundant rainfall, mild climate and sufficient light, and is located in an area rich in hydraulic resources, with soils including red loam, yellow loam, alluvial soil, rice soil and other types, rich in organic matter. Especially in mineral resources, the mineral resources in Huangtian town are very rich, mainly selenium, tin, marble, rare earths, especially marble resources are the most abundant, known for the production of "Guangxi white" marble. The village has a long history and simple folk culture, and it has preserved the famous Fushan Temple site, which is a cultural relic protection site in Hezhou City, and collected many ancient monuments.

\subsection{Vernacular landscape elements and spatial layout}

Some scholars have different understandings of the elements of the vernacular landscape, including weather, seasons and settlements based on the three talents of "heaven, earth and man", some divide mountains, water, forests, fields and lakes based on the elements of landscape construction. Based on the "three living spaces" in the village planning, the elements are divided into three categories: ecology, production and life, and the framework table is drawn for each specific element.

Table 1. Summary Table of Vernacular Landscape Elements in Changlong Village

\begin{tabular}{|c|c|c|}
\hline Landscape category & Landscape unit & concrete element \\
\hline \multirow{2}{*}{ Ecological elements } & Climate & Sunshine, rainfall, wind, frost \\
\cline { 2 - 3 } & Terrain & Plains, hills, mountains (karst landscapes) \\
\hline
\end{tabular}




\begin{tabular}{|c|c|c|}
\hline & Soil & $\begin{array}{l}\text { Red soil, yellow soil, alluvial soil, limestone soil, } \\
\text { purple soil, rice soil }\end{array}$ \\
\hline & Vegetation & $\begin{array}{l}\text { Evergreen broad-leaved forest, deciduous broad- } \\
\text { leaved forest, grassland }\end{array}$ \\
\hline & Hydrology & Ponds, drains \\
\hline \multirow{4}{*}{ Production factors } & Arable land & Paddy, dryland, vegetable, farmland pattern \\
\hline & Agricultural activities & $\begin{array}{c}\text { Irrigation, transportation, labor scenes, livestock, } \\
\text { field trails }\end{array}$ \\
\hline & Productive forest land & Fruit orchards (Citrus, etc.), economic forests \\
\hline & Mining land & $\begin{array}{l}\text { Selenium, tin, lead, zinc, iron, gold, arsenic, } \\
\text { marble, rare earths, quartz }\end{array}$ \\
\hline \multirow{6}{*}{ Life factors } & Rural Settlements & Village pattern, road system, activity plaza \\
\hline & Construction & $\begin{array}{c}\text { Ancestral buildings (Mo's Ancestral Hall), temples } \\
\text { and Taoist temples (North Pole Temple, Qifeng } \\
\text { Temple, Fushan Temple), traditional buildings, } \\
\text { residential houses, factories (breeding, steel), } \\
\text { public buildings (schools, hospitals), project } \\
\text { construction buildings }\end{array}$ \\
\hline & Vernacular materials & Stone (marble, etc.), wood, native plants \\
\hline & Landscaping & Garbage pits, signs, street lights, brick piles \\
\hline & customs and folklore & $\begin{array}{c}\text { Inertia Festival, Ancestral worship, "March 3", } \\
\text { Fairs }\end{array}$ \\
\hline & Religious beliefs & Buddhism, Taoism \\
\hline
\end{tabular}

The spatial layout of the elements of the vernacular landscape can be combined with the village land use division of the three tunes to divide it into agricultural land, construction land and ecological land, with agricultural land linked to production elements, construction land linked to production and living elements, and ecological land linked to ecological elements, so as to grasp the general spatial layout of landscape elements as a whole.

\subsection{The current situation and problems of the protection of vernacular landscape}

From the results of the field survey, the vernacular landscape of Changlong Village is facing the following problems. (1) The extinction of characteristic culture. This is mainly due to the rapid development of modern society and the uniform village planning, which makes the difference more and more missing. (2) The natural ecological texture is broken. For some native bamboo forests, tree woodlands are cut down for building houses, and there is no plant configuration inside the village at all, which destroys the ecological traffic inside and outside the village and reduces biodiversity. (3) Destruction of farmland production landscape. Not only has the expansion of village buildings encroached on large areas of farmland, but most have villagers switched to vegetable farming for economic benefits, which has a huge impact on the rural landscape, which is mainly farmland production. (4) The conflict between traditional architecture and modern architecture. Most villagers in Changlong Village have refurbished their houses, preferring to imitate European-style architecture, and traditional architecture is almost extinct. (5) The lack of activity squares and other living landscapes. Fieldwork shows that there are only three activity sites in Changlong Village, which are far from meeting the needs of the seven natural villages in Changlong Village. And there is a lack of practical public buildings such as toilets, which adversely affects the living landscape in the village. (6)
Weak awareness of village planning and design. The planning of Changlong Village stays more in the shallow design, not only the villagers' awareness of landscape protection, but also the design focus of the planning and design staff.

\subsection{Vernacular landscape protection planning}

(1) Positioning. The development potential of Changlong Village is evaluated according to its natural endowment, socio-economic and planning position, and its development is positioned as an agricultural, cultural, tourism and recreational village with the landscape features of "green mountains, beautiful forests, fertile fields, blue water, sweet springs, and spiritual Buddha". The village planning mainly includes industrial development, land use layout, land space improvement, etc. The protection of native landscape is mostly seen in the ecological restoration level of land use layout and space improvement, the specific native landscape protection system or village landscape protection system is not established, and the orientation of native landscape protection is not clear.

(2) Layout. The village layout is divided into three major areas: sugar orange plantation area, cultural tourism comprehensive development area, and idyllic green valley resort area. Relying on the existing sugar orange plantation, it develops tourism projects such as sugar orange picking and study, etc. Relying on the karst valley idyllic landscape, it builds the idyllic green valley resort area which integrates study trip and recreation, and relies on the thousand mu Xiufeng Lake, karst topography and ecological idyllic landscape planned by the idyllic complex to build ecological landscapes such as flower fields, wetlands and forests. The overall layout is relatively clear, with ecological production first and construction second, and the planning of construction land under the condition of ensuring ecological and production safety, which is basically in line with the overall layout of 
sustainable development.

(3) Strategy.

(1)Field study, GIS technology application. Use GIS analysis to evaluate the spatial layout of landscape resources, reproduce rural memories by giving specific material carriers to achieve element reproduction, or mend some of the destroyed traditional material carriers through compensatory means. (2)Integration of the government and the people and participation of many parties. The Bureau of Natural Resources of Pinggui District, Huangtian Township Government, Changlong Village Committee, villagers, and the technical team of planning preparation participated in multiple parties, collecting opinions and suggestions from the village committee and villagers extensively through field research, interviews, and talks with the village committee and villagers, and taking the pulse of the pain points of village development. (3) Cultural and tourism integration, project driven. Due to the construction projects such as the field complex of Changlong Village, the traditional culture of the village and local elements can be displayed through tourism, which not only brings financial income but also promotes the village. By applying for funding for projects such as leisure agriculture tourism development and construction of agricultural trade and logistics service system, we promote the construction of rural infrastructure and basic public service facilities as well as ecological governance. (4) Multi-planning and joint supervision. The village planning of Changlong contains many types of projects such as traditional village protection planning, ecological red line protection, etc. By screening and extracting the vernacular landscape elements in each category, we can grasp the vernacular landscape protection of Changlong village as a whole. Secondly, the governments of Pinggui District and Huangtian Town lead the way and set up a village planning implementation testing and supervision group, and incorporate the planning implementation into the annual assessment of the village committee. (5)Talent introduction and innovation drive. Increase the efforts of enterprises or individuals to develop rural businesses, introduce policies to protect the future development of farmers, and innovate the cooperative business model of "enterprise + farmer" to solve the problems of narrow marketing, difficult sales or lack of price guarantee for agricultural products, and promote the industrialization and large-scale development of agriculture.

\section{Conclusion}

In general, the vernacular landscape conservation planning of Changlong Village is in line with the real situation of most rural areas in China. Compared with western countries, China's vernacular landscape conservation planning is still in the primary stage and needs further development. In the context of rural revitalization, only by establishing a vernacular landscape or rural landscape protection system, deeply understanding the cultural connotation and regional style of the village, analyzing its vernacular landscape, and combining the villagers' wishes with the protection plan, can we show the pattern of "a hundred flowers blooming".
At the same time, modern technology can be used to link the historical heritage and future development into the real village and promote the establishment of a practical village. Only when preservation and development go hand in hand can we truly promote the revitalization and vitality of rural areas and achieve sustainable development.

\section{Acknowledgments}

This article is one of the phased results of the key support project of the Ministry of Culture and Tourism for graduate students "Research on the Integrated Development Path of Guangxi Zhuang Nationality's Traditional Sports Culture and Tourism from the Perspective of Cultural Experience" (WLRCY2019-070) and the Guangxi Postgraduate Innovation Plan Project "Analysis of the Temporal and Spatial Patterns of Guangxi Tourism Development and Optimization Strategies" (YCSW2019164).

\section{References}

1. Harvey, D.K. (1984) Discovering the Vernacular Landscape (Book). J. Library Journal.

2. Nazar, B.E., Andaroodi, E., Sahrakaran, B. (2017) Vernacular Cultural Landscape of Qazvin's Traditional Gardens: A Review of Basic Conepts and Analysis of Elements and Features within the Scope of Built Environment. J. Bagh-E Nazar., 14(50): 3948.

3. Zhang, J.S. (2013) An overview of the development of the Dutch rural landscape in the 20th century. J. Landscape Architecture., (04): 61-66.

4. Hou, X.L ,Guo.W. (2015) Place and nostalgia--an exploration of the research method of rural landscape in landscape gardening vision. J. Urban Development Research., 22(4): 80-85.

5. Yu, K.J., Wang,Z.F., Huang, G.P. (2005) On vernacular landscape and its significance to modern landscape design. J. Huazhong Architecture., 23(4): 123-126

6. Liu, L.M. (2001) The development history of rural landscape planning and its development prospect in China. J. Rural Ecology., 17(1): 52-55.

7. Liu, L.M., Li, Z.P., Zhang, H.B. (2004) The characteristics of rural landscape in China and the objectives and contents of rural landscape planning. J. Ecological Environment., 13(3): 445-448. 